Article

\title{
Facile Synthesis of 3-(Azol-1-yl)-1-adamantanecarboxylic Acids-New Bifunctional Angle-Shaped Building Blocks for Coordination Polymers
}

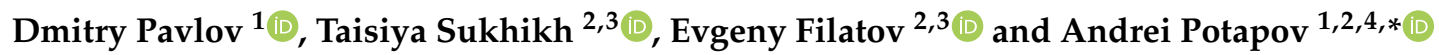 \\ 1 Kizhner Research Center, National Research Tomsk Polytechnic University, 30 Lenin Ave., \\ 634050 Tomsk, Russia \\ 2 Nikolaev Institute of Inorganic Chemistry, Siberian Branch of the Russian Academy of Sciences, 3 Lavrentiev \\ Ave., 630090 Novosibirsk, Russia \\ 3 Department of Natural Sciences, Novosibirsk State University, 2 Pirogov Str., 630090 Novosibirsk, Russia \\ 4 Department of Chemical Technology, Polzunov Altai State Technical University, 46 Lenin Ave., \\ 656038 Barnaul, Russia \\ * Correspondence: potapov@niic.nsc.ru; Tel.:+79234034103; Fax: +73833309489
}

Received: 4 July 2019; Accepted: 26 July 2019; Published: 26 July 2019

check for updates

\begin{abstract}
For the first time, orthogonally substituted azole-carboxylate adamantane ligands were synthesized and used for preparation of coordination polymers. The angle-shaped ligands were prepared by the reaction of 1-adamantanecarboxylic acid and azoles (1H-1,2,4-triazole, 3-methyl-1H-1,2,4-triazole, 3,5-dimethyl-1H-1,2,4-triazole, $1 H$-tetrazole, 5-methyl-1H-tetrazole) in concentrated sulfuric acid. Variation of the solvent and substituents in azole rings allowed to prepare both $1 \mathrm{D}$ and $2 \mathrm{D}$ copper(II) and nickel(II) coordination polymers, $\left[\mathrm{Cu}_{2}(\text { trzadc })_{4}\left(\mathrm{H}_{2} \mathrm{O}\right)_{0.7}\right] \cdot \mathrm{DMF} \cdot 0.3 \mathrm{H}_{2} \mathrm{O},\left[\mathrm{Cu}(\operatorname{trzadc})_{2}(\mathrm{MeOH})\right] \cdot \mathrm{MeOH},\left[\mathrm{Ni}(\operatorname{trzadc})_{2}(\mathrm{MeOH})_{2}\right]$ and $\left[\mathrm{Cu}_{2}(\text { mtrzadc })_{3}(\mathrm{MeOH})\right]^{+} \mathrm{NO}_{3}{ }^{-}$(trzadc-3-(1,2,4-triazol-1-yl)-adamantane-1-carboxylic acid; mtrzadc-3-(3-methyl-1,2,4-triazol-1-yl)-adamantane-1-carboxylic acid) which were structurally characterized by single crystal X-ray diffraction. Complex $\left[\mathrm{Cu}(\operatorname{trzadc})_{2}(\mathrm{MeOH})\right] \cdot \mathrm{MeOH}$ was shown to act as a catalyst in the Chan-Evans-Lam arylation reaction.
\end{abstract}

Keywords: adamantane; carboxylate ligands; chain structures; heterocyclic ligands; metal-organic frameworks

\section{Introduction}

Adamantane has been recognized for a long time as an important molecule for crystal design. An example of exploiting the potential of the adamantane moiety is 1,3,5,7-tetrakis(1,2,4-triazol-4-yl)adamantane [1], but even more simple 1,3,5,7-adamantanetetracarboxylic acid can produce spectacular frameworks [2]. A number of different adamantane derivatives have been designed and their coordination ability explored [3-14].

Metal-organic frameworks (MOFs) that feature metal ions with a 'mixed' coordination environment are often of great interest [15], and in case of adamantane usually achieved through a 'mixed-ligand' approach [16], which turns a two-component reaction into a much more complicated system, reducing reproducibility and ease of handling. One way to avoid this problem is to combine various functions in a single molecule, but no examples of coordination compounds built using two or more different donor groups linked by an adamantane backbone have been reported so far. This fact is probably due to synthetic difficulties in such functionalization [3,17]. Functional moieties with different coordination 
modes linked by a rigid platform like adamantane may be expected to form structures with complex geometry of great interest; producing a 'mixed' coordination environment for metal ion, so looking for ways to synthesize such species is always an actual challenge.

Following our interest in adamantane-based ligands [18], in this paper, we would like to communicate a method for the synthesis of the new adamantane-based ligands-3-(1,2,4triazol-1-yl)-1-adamantanecarboxylic acid, 3-(tetrazol-1-yl)-1-adamantanecarboxylic acid and their methyl derivatives. Along with synthesis of new ligands themselves, several coordination polymers were synthesized and structurally characterized.

\section{Results and Discussion}

\subsection{Symthetic Approach}

For the synthesis of ligands, we employed the very well-known property of adamantane to form a carbocation with the charge localized at bridgehead carbon under highly acidic conditions [19-21] (Scheme 1).


mtrzadcH, $65 \%$
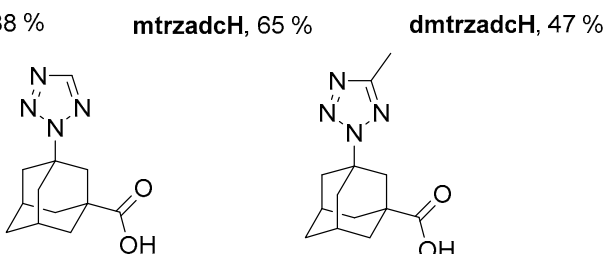

ttzadcH, $81 \%$

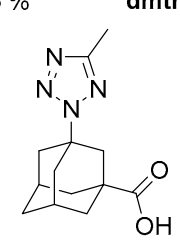

mttzadcH, $76 \%$

Scheme 1. Reaction scheme between azoles (AzH) and 1-adamantanecarboxylic acid.

This reaction went smoothly for both unsubstituted and 3,5-substituted 1,2,4-triazoles, as well as tetrazoles-much to our surprise, because usually, adamantylation of azoles can be achieved by substitution reaction of bromo- or hydroxy- groups [22-26]. Despite the fact that the carboxylic moiety destabilizes adamantyl cations to a significant extent, the reaction between azoles and 1-adamantanecarboxylic acid proceeded smoothly and gave new bifunctional adamantane derivatives in good yields. Hence, this reaction is an example of useful C-H functionalization.

To further explore interactions of 1-adamantylcarboxylic acid with different azoles, we attempted the same procedure for diazoles, but reactions with both pyrazole and imidazole were unsuccessful, and gave 3-hydroxyadamantane 1-carboxylic acid as products with $65 \%$ yield.

These observations correspond well with previous studies on the reactivity of azoles and adamantyl cations in acidic media [22-26], where it was determined that adamantylation with 1-adamantanol is possible with fairly acidic pyrazoles, the approximate limit to the $\mathrm{pK}_{\mathrm{BH}}+$ being 0.8 [26]. Acidities of both unsubstituted pyrazole and imidazole are much lower (0.47 and 0.39) than that value [27].

\subsection{Synthesis and IR Spectra of Coordination Polymers}

Reaction of trzadcH with copper(II) and nickel(II) nitrates in methanol at 4:1 ratio afforded pale-blue and pale-green crystalline 1D coordination polymers 2 and 3. Reaction with copper nitrate in 
DMF at the same ratio afforded bright-blue crystals 1 with different composition. At the same time, some amorphous green product precipitated. The reaction in dry DMF afforded only amorphous green solid, which turned blue on prolonged exposure to air. All attempts to obtain a crystalline form of this product have failed and no other attempts at characterization of the compound were made. Pure compound 1 could be prepared by addition of an equimolar amount of water. Reaction of mtrzadcH with copper(II) nitrate in methanol yielded bright-green crystals of 2D coordination polymer 4, its higher dimensionality is probably due to the additional steric hindrance introduced by methyl group (see discussion below).

All of the IR spectra demonstrate coordination-induced shifts of bands corresponding to vibrations of azole rings and carboxylic groups (Figure S7).

The broad band at $3456 \mathrm{~cm}^{-1}$ in the spectrum of compound 1 can be attributed to lattice water. Bands of asymmetric and symmetric carboxylic C-O stretching vibrations appear at $1578 \mathrm{~cm}^{-1}$ and $1350 \mathrm{~cm}^{-1}\left(\Delta 228 \mathrm{~cm}^{-1}\right)$ compared to $1682 \mathrm{~cm}^{-1}$ and $1229 \mathrm{~cm}^{-1}\left(\Delta 453 \mathrm{~cm}^{-1}\right)$ in the uncoordinated ligand. For compounds 2 and 3 separation between carboxylic stretching vibration bands $(\Delta)$ is 265 and $185 \mathrm{~cm}^{-1}$, respectively. In case of compound $4, \Delta$ value is $314 \mathrm{~cm}^{-1}$. These observations are consistent with non-equivalence of metal-oxygen bonds in compounds 1-4 evident from structural data $[28,29]$. Stretching $\mathrm{OH}$ vibration bands of uncoordinated methanol can be seen in the spectrum of compound 2 at $3381 \mathrm{~cm}^{-1}$ but in the spectra of compounds 3 and 4 with coordinated methanol molecules these bands were not detected. Extremely intense band at $1415 \mathrm{~cm}^{-1}$ in the spectrum of compound 4 indicates the presence of uncoordinated $\mathrm{NO}_{3}{ }^{-}$ion.

\subsection{Crystal Structure of 3-(1,2,4-Triazol-1-yl)-1-adamantanecarboxylic Acid}

Compound trzadcH crystallizes in a monoclinic crystal system, $P 2_{1} / n$ space group, the unit cell contains four formula units of the compound (Figure 1). The molecules of trzadcH are involved in $\mathrm{O}-\mathrm{H} \cdots \mathrm{N}$ intermolecular hydrogen bonding via carboxylic groups and nitrogen atoms in position 4 of 1,2,4-triazole cycles ( $\mathrm{O} \cdots \mathrm{N}$ distance of $2.677 \AA$, $\mathrm{O}-\mathrm{H} \cdots \mathrm{N}$ angle of $\left.165.48^{\circ}\right)$. Hydrogen bonds link the molecules into $1 \mathrm{D}$ chains, oriented at an angle of 39.2 degrees to the $c$ axis (Figure S5).

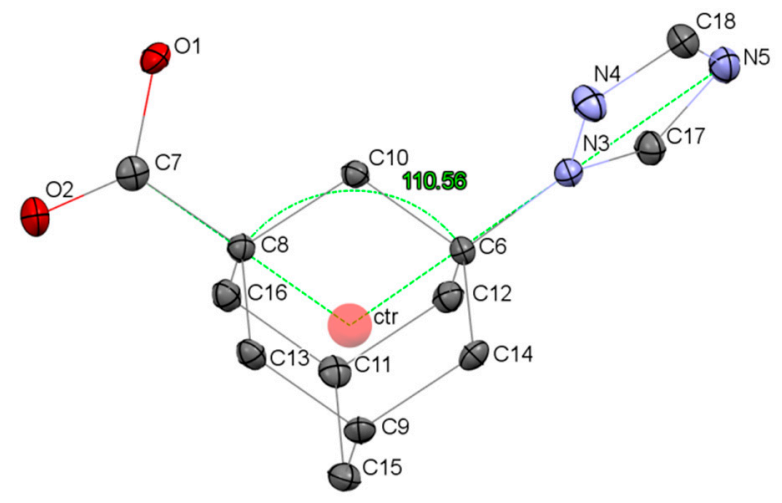

Figure 1. The structure of the compound trzadcH showing adamantane centroid (ctr) and $\phi \mathrm{CctrN}$ angle. $\mathrm{H}$ atoms are omitted.

In order to describe and compare the geometries of different angle-shaped N,O-ligands, we defined the angle $\phi_{C \text { ctrN }}$ comprising the carbon atom of the carboxylic group, the centroid of the linker (adamantine in our case) and nitrogen donor atom ( $\mathrm{N}$ atom at position 4 of triazole ring for compound trzadcH). The value of this angle for trzadcH $\left(110.6^{\circ}\right)$ is noticeably different from $\phi_{C c t r N}$ values calculated for most of other angle-shaped ligands commonly used for the synthesis of coordination polymers (Table 1), indicating the perspectivity of the synthesized family of ligands for the construction of coordination polymers with new topologies. 
Table 1. Angle-shaped ligands commonly used for the synthesis of coordination polymers.



\subsection{Crystal Structures of Coordination Polymers}

The non-isostructural complexes 1-3 are 1D coordination polymers revealing the bridging nature of the trzadc ${ }^{-}$ligand (Figures 2 and 3). It coordinates to the metals via one $\mathrm{N}$ of triazole and one $\mathrm{O}$ atom of carboxyl moiety to form 1D chains. Two trzadc ${ }^{-}$are arranged between adjacent central atoms; thus, the ligands occupy four coordination sites of the metal forming a square environment. Other sites are occupied by water or methanol: two molecules in the complex 2, revealing octahedral coordination environment of $\mathrm{Ni}$, and one molecule in 3 with a square pyramidal arrangement of $\mathrm{Cu}$. Compound 1 contains the first $\mathrm{Cu}$ atom in a square planar environment (without solvent molecules), while the second $\mathrm{Cu}$ atom features partially occupied (of 70\%) water molecules in a coordination shell according to analysis of residual electron density map (Figure S14). Thus, this $\mathrm{Cu}$ atom has a mixed square pyramidal/square planar environment. The reason for partial occupancy of water can be corresponding with the bond distance $\mathrm{Cu}-\mathrm{O}$ of $2.40 \AA$, being longer than typical $\mathrm{Cu}-\mathrm{OH}_{2}$ bonds (of 1.95-2.20 $\AA$ ) found in CSDB (v. 5.40, February 2019). As a result, the weak Cu-O interaction leads to defects in the crystal packing. Note that structure 1 contains partially occupied (of $30 \%$ ) solvate water molecule close to coordinated one. However, they do not compete for the formation of hydrogen bonds (Figure S1a), and there is enough space in the structure for their joint presence. 


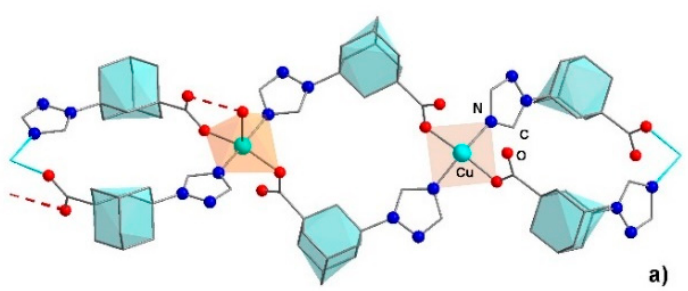

(a)



(b)

Figure 2. The structure of $1 \mathrm{D}$ chain of the complexes $\mathbf{1}(\mathbf{a})$ and $\mathbf{2}(\mathbf{b})$. Adamantane units are coloured blue, coordination polyhedra of the central atoms are coloured orange. Hydrogen atoms and solvate molecules are omitted; dashed red lines indicate intramolecular hydrogen bonds.

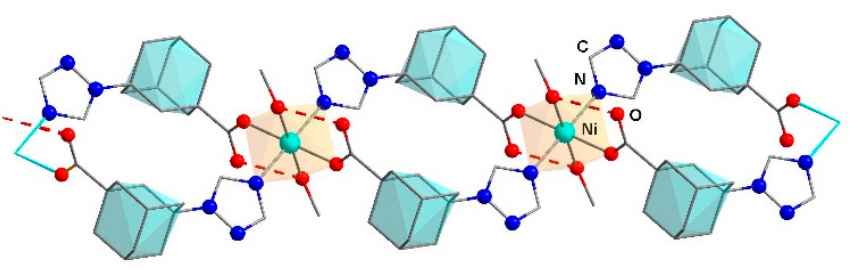

(a)

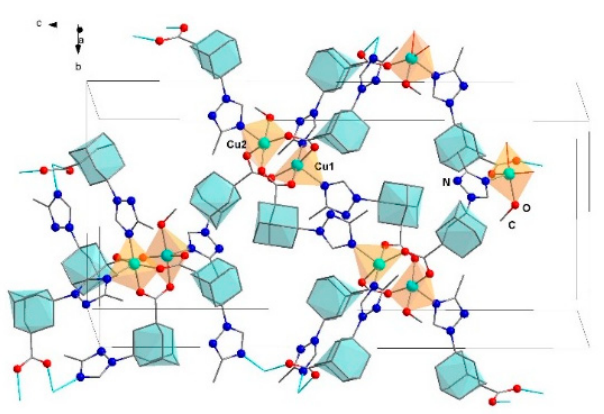

(b)

Figure 3. The structure of 1D chain of the complex 3 (a) and structure of the complex 4 (b). Adamantane units are coloured blue, coordination polyhedra of the central atoms are coloured orange. Hydrogen atoms and nitrates are omitted; dashed red lines indicate intramolecular hydrogen bonds.

Overall geometry and crystal packing of 1D chains of complexes 1-3 are somewhat close (Figure S2). However, in 3, adamantane units are arranged on one side from the CuNO plane (Figure S3), while in 1 and 2, adamantane units lie on both sides of the corresponding plane. Furthermore, complex 3 reveals tight packing of the chains (with intramolecular hydrogen bonds between the methanol and carboxyl moiety), while $\mathbf{1}$ and $\mathbf{2}$ have solvate DMF, water or methanol molecules filling the space between the chains. The solvate molecules connect the chains via hydrogen bonds forming 2D-layered structures (Figure S1).

The structure of complex 4 significantly differs from that of 1-3 because of the presence of a methyl substituent in the triazole moiety. This group prevents arrangement of the ligands to form a square coordination environment of $\mathrm{Cu}$, which is observed for 1-3. Instead, pentagonal pyramidal environment is implemented in $\mathbf{4}$ with two $\mathrm{N}$ atoms in apical and basal positions for the first $\mathrm{Cu}$ atom and one $\mathrm{N}$ atom in the apical position for the second one (Figure 3 ). The latter further coordinates the methanol molecule. In contrast to 1-3, the carboxylate moiety serves as a bridging group connecting two adjacent central atoms. Thus, a 2D-layered structure of 4 is observed.

In principle, trzadc $^{-}$and mtrzadc $^{-}$ligands have two degrees of freedom, viz. rotation of triazole around $\mathrm{C}-\mathrm{N}$ bond and rotation of carboxyl moiety around $\mathrm{C}-\mathrm{O}$ bond (Figure S4). According to analysis of the corresponding torsion angles (Table S2), conformation of the ligand can vary within certain limits, adjusting to the central atom environment.

\subsection{Powder X-Ray Diffraction and Thermal Studies}

Powder X-Ray diffraction was used to confirm phase purity of the bulk product. As experimental PXRD patterns match simulated ones sufficiently (Figure S5), we conclude that synthesis provides product of high purity with good crystallinity.

All of the coordination polymers demonstrate similar thermal stability. (Figure S8) In case of $\mathbf{1}$, only DMF molecules are lost during the initial step $\left(219-281^{\circ} \mathrm{C}\right)$-calc. mass loss $5.98 \%$, observed 
$6.13 \%$. Water loss along with the gradual organic ligand degradation started at $315^{\circ} \mathrm{C}$ and completed at $430{ }^{\circ} \mathrm{C}$. Compound 2 loses one uncoordinated methanol molecule during the first thermolysis step (90-200 ${ }^{\circ} \mathrm{C}$ ), followed by deep degradation of the ligand and coordinated methanol loss in the range of $270-580{ }^{\circ} \mathrm{C}$. As for 3, coordinated methanol molecules remain bond up to the temperature of $190{ }^{\circ} \mathrm{C}$, then a mass loss of $10.2 \%$ occurs, corresponding to two methanol molecules (calc. $10.4 \%$ ). Coordination of polymer 4 demonstrated an extremely exothermic decomposition process in the range of $220-260{ }^{\circ} \mathrm{C}$ with a rapid mass loss, consistent with the presence of nitrate ions.

\subsection{Catalytic Activity Studies}

Considering a vacant coordination site of a copper atom in compound 2 and coordinated solvent molecules in compounds $\mathbf{1}$ and $\mathbf{3}$, as well as numerous applications of chain coordination polymers as catalysts $[39,40]$, we decided to test their catalytic activity for the Chan-Evans-Lam N-arylation reaction (CEL arylation), which is known to be efficiently catalysed by various metal complexes [41] and copper salts [42].

We found that compound 2 serves as an efficient catalyst for the CEL arylation reaction, with imidazole and phenylboronic acid as model substrates (Scheme 2). The reaction was performed at $40^{\circ}$ using methanol as a solvent on air with 1:1.5 molar ratio of reagents adding $5 \mathrm{~mol} \%$ of the catalyst. With these conditions, we achieved 99\% conversion (GC) of the starting imidazole after $24 \mathrm{~h}$.

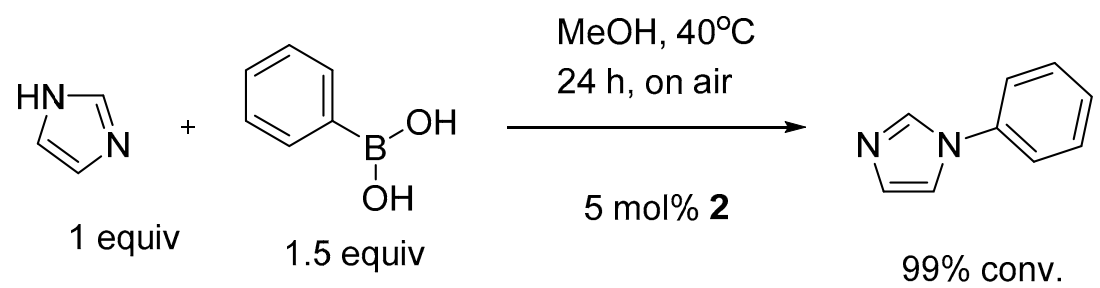

Scheme 2. Model reaction for the investigation of catalytic properties of polymer 2.

Interestingly enough, compound $\mathbf{1}$ demonstrated no catalytic activity in this reaction, as well as 3 and 4 (Table 2, entries 8-9), which allows us to conclude that not only copper itself is crucial, but also its coordination environment, being square planar in $\mathbf{2}$ and mixed square pyramidal/square planar in $\mathbf{1}$. Also, it might be due to stronger bonding of water compared to the methanol molecules.

Table 2. Influence of the reaction conditions and catalyst choice on the result of the reaction.

\begin{tabular}{ccc}
\hline Entry & Solvent & Result \\
\hline 1 & Methanol $^{\mathrm{a}}$ & $99 \%$ conversion \\
2 & Methanol $^{\mathrm{a}}$ & $60 \%$ conversion \\
3 & Methanol $^{\mathrm{b}}$ & $92 \%$ conversion \\
4 & DMSO & - \\
5 & Water & - \\
6 & Dichloromethane & $13 \%$ conversion \\
7 & Ethanol $^{\mathrm{c}}$ & $15 \%$ conversion \\
8 & Methanol $^{\mathrm{c}}$ & - \\
9 & Methanol $^{\mathrm{d}}$ & No reaction \\
\hline
\end{tabular}

Reaction conditions: 0.1 mmole imidazole $(6.3 \mathrm{mg}), 0.15 \mathrm{mmoles}(18,3 \mathrm{mg})$ phenylboronic acid, $6 \mathrm{mg}$ compound 2, $1 \mathrm{~mL}$ methanol, $40^{\circ} \mathrm{C}, 24 \mathrm{~h}$ on air.-Degradation of the polymer. a-reaction at room temperature. $\mathrm{b}-0.12 \mathrm{mmoles}$ $(14,6 \mathrm{mg})$ of phenylboronic acid were used. c - $\mathbf{4}$ was used as a catalyst, $\mathrm{d}-\mathbf{1}$ or $\mathbf{3}$ were used as catalysts.

Furthermore, we found that methanol is an essential condition for the success of the reaction. We have tested a number of different solvents, some of them gave low conversions and in some cases, the polymer had dissolved completely (DMSO and water), in case of ethanol, partial dissolution was also noted; all results are summarized in Table 3. 
Table 3. Crystallographic data of the ligand trzadcH and the complexes 1-4.

\begin{tabular}{|c|c|c|c|c|c|}
\hline Compound & trzadcH & 1 & 2 & 3 & 4 \\
\hline Empirical formula & $\mathrm{C}_{13} \mathrm{H}_{17} \mathrm{~N}_{3} \mathrm{O}_{2}$ & $\mathrm{C}_{55} \mathrm{H}_{73} \mathrm{Cu}_{2} \mathrm{~N}_{13} \mathrm{O}_{10}$ & $\mathrm{C}_{55} \mathrm{H}_{76} \mathrm{Cu}_{2} \mathrm{~N}_{12} \mathrm{O}_{11}$ & $\mathrm{C}_{28} \mathrm{H}_{40} \mathrm{~N}_{6} \mathrm{NiO}_{6}$ & $\mathrm{C}_{43} \mathrm{H}_{58} \mathrm{Cu}_{2} \mathrm{~N}_{10} \mathrm{O}_{10}$ \\
\hline Formula weight & 247.29 & 1203.34 & 1208.35 & 615.37 & 1002.07 \\
\hline Space group & $P 2_{1} / n$ & $P-1$ & $P-1$ & $P-1$ & $P 2_{1} / c$ \\
\hline $\mathrm{a} / \AA$ & $11.1449(11)$ & $12.0509(5)$ & $6.6424(2)$ & $6.6392(5)$ & $10.1256(3)$ \\
\hline $\mathrm{b} / \AA \AA$ & $6.7467(5)$ & $13.5356(5)$ & $12.0031(4)$ & $9.7528(7)$ & $14.5363(4)$ \\
\hline$c / \AA$ & $15.3121(17)$ & $17.4158(8)$ & $17.8350(6)$ & $11.6021(8)$ & $30.4164(8)$ \\
\hline$\alpha /^{\circ}$ & 90 & $97.022(2)$ & $70.4510(10)$ & $66.060(2)$ & 90 \\
\hline$\beta /^{\circ}$ & $100.142(10)$ & 108.9450(10) & $81.2370(10)$ & $81.403(2)$ & $95.9110(10)$ \\
\hline$\gamma /^{\circ}$ & 90 & $95.3130(10)$ & $81.8090(10)$ & $74.214(2)$ & 90 \\
\hline Volume $/ \AA^{3}$ & $1133.35(19)$ & $2640.15(19)$ & $1317.96(7)$ & $660.07(8)$ & $4453.1(2)$ \\
\hline $\mathrm{Z}$ & 4 & 2 & 1 & 1 & 4 \\
\hline$\rho_{\text {calc }} \mathrm{g} / \mathrm{cm}^{3}$ & 1.449 & 1.514 & 1.522 & 1.548 & 1.495 \\
\hline$\mu / \mathrm{mm}^{-1}$ & 0.100 & 0.880 & 0.883 & 0.792 & 1.025 \\
\hline $\mathrm{F}(000)$ & 528.0 & 1264.0 & 636.0 & 326.0 & 2096.0 \\
\hline Crystal size $/ \mathrm{mm}^{3}$ & $0.17 \times 0.15 \times 0.08$ & $0.27 \times 0.13 \times 0.08$ & $0.3 \times 0.15 \times 0.12$ & $0.31 \times 0.18 \times 0.17$ & $0.35 \times 0.3 \times 0.22$ \\
\hline $\begin{array}{l}2 \Theta \text { range for data } \\
\text { collection/ }^{\circ}\end{array}$ & 6.52 to 62.93 & 3.61 to 52.746 & 3.66 to 57.612 & 3.844 to 57.49 & 3.108 to 57.488 \\
\hline Index ranges & $\begin{array}{c}-14 \leq \mathrm{h} \leq 12 \\
-8 \leq \mathrm{k} \leq 8 \\
-19 \leq 1 \leq 19\end{array}$ & $\begin{array}{l}-15 \leq \mathrm{h} \leq 15 \\
-16 \leq \mathrm{k} \leq 14 \\
-21 \leq 1 \leq 21\end{array}$ & $\begin{aligned}-8 & \leq \mathrm{h} \leq 8 \\
-16 & \leq \mathrm{k} \\
-24 & \leq 16 \\
-2 & \leq 24\end{aligned}$ & $\begin{aligned} &-8 \leq \mathrm{h} \leq 8 \\
&-13 \leq \mathrm{k} \\
&-15 \leq 13 \\
&-15\end{aligned}$ & $\begin{array}{l}-13 \leq \mathrm{h} \leq 13 \\
-15 \leq \mathrm{k} \leq 19 \\
-38 \leq 1 \leq 41\end{array}$ \\
\hline Reflections collected & 9394 & 30381 & 20394 & 12721 & 62483 \\
\hline Independent reflections & $\begin{array}{c}2601\left[R_{\text {int }}=0.0460,\right. \\
\left.R_{\text {sigma }}=0.0505\right]\end{array}$ & $\begin{array}{c}10753\left[R_{\text {int }}=0.0320,\right. \\
\left.R_{\text {sigma }}=0.0425\right]\end{array}$ & $\begin{array}{c}6840\left[R_{\text {int }}=0.0238,\right. \\
\left.R_{\text {sigma }}=0.0246\right]\end{array}$ & $\begin{array}{c}3415\left[R_{\text {int }}=0.0241,\right. \\
\left.R_{\text {sigma }}=0.0194\right]\end{array}$ & $\begin{array}{c}11544\left[R_{\text {int }}=0.0270,\right. \\
\left.R_{\text {sigma }}=0.0182\right]\end{array}$ \\
\hline parameters & 164 & 737 & 364 & 189 & 591 \\
\hline Goodness-of-fit on $\mathrm{F}^{2}$ & 1.027 & 1.023 & 1.053 & 1.055 & 1.045 \\
\hline Final $\mathrm{R}$ indexes $[\mathrm{I}>=2 \sigma(\mathrm{I})]$ & $\begin{array}{r}\mathrm{R}_{1}=0.0463 \\
\mathrm{wR}_{2}=0.0923\end{array}$ & $\begin{array}{r}\mathrm{R}_{1}=0.0405 \\
\mathrm{wR}_{2}=0.0971\end{array}$ & $\begin{array}{r}\mathrm{R}_{1}=0.0385 \\
\mathrm{wR}_{2}=0.1029\end{array}$ & $\begin{array}{r}\mathrm{R}_{1}=0.0269 \\
\mathrm{wR}_{2}=0.0732\end{array}$ & $\begin{array}{c}\mathrm{R}_{1}=0.0272 \\
\mathrm{wR}_{2}=0.0704\end{array}$ \\
\hline Final $\mathrm{R}$ indexes [all data] & $\begin{array}{c}\mathrm{R}_{1}=0.0733 \\
\mathrm{w} \mathrm{R}_{2}=0.1026\end{array}$ & $\begin{array}{r}\mathrm{R}_{1}=0.0558 \\
\mathrm{wR}_{2}=0.1044\end{array}$ & $\begin{array}{r}\mathrm{R}_{1}=0.0427 \\
\mathrm{wR}_{2}=0.1059\end{array}$ & $\begin{array}{r}\mathrm{R}_{1}=0.0280 \\
\mathrm{wR}_{2}=0.0739\end{array}$ & $\begin{array}{r}\mathrm{R}_{1}=0.0312 \\
\mathrm{wR}_{2}=0.0723\end{array}$ \\
\hline Largest diff. peak/hole/e $\AA^{-3}$ & $0.34 /-0.24$ & $1.03 /-0.53$ & $1.51 /-0.70$ & $0.68 /-0.46$ & $0.48 /-0.34$ \\
\hline
\end{tabular}

Additionally, we investigated the influence of reactant ratios and temperature. The reaction does occur at the room temperature, but it is inefficiently slow (Table 2, entry 2), giving only $60 \%$ conversion in $24 \mathrm{~h}$. A decrease of the amount of boronic acid leads to the decrease of conversion (92\%, Table 2, entry 3).

To elucidate the possibility of the homogenous catalysis happening and to prove our claim for the recyclability of the catalyst, we recovered the compound after running a reaction in a single cycle and run PXRD on the recovered sample (Figure 4). The sample was washed with methanol and dried on air prior to analysis.

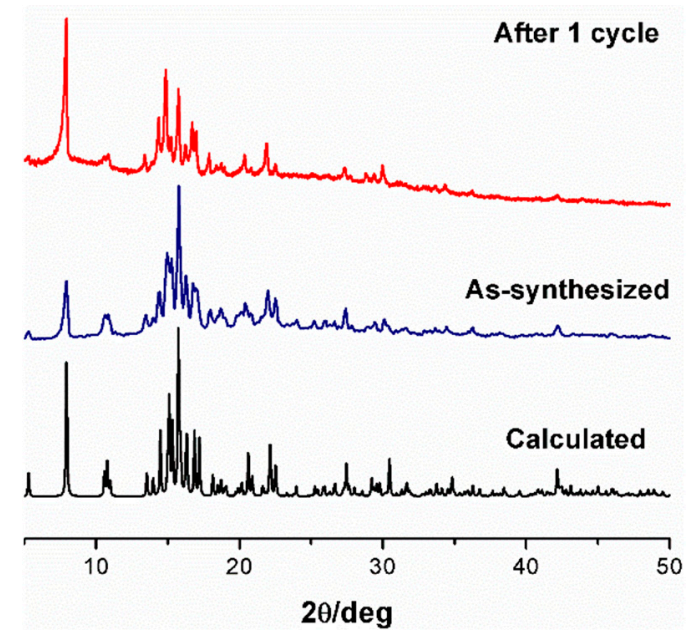

Figure 4. PXRD of the compound 2 before and after running the reaction.

As evident from the diffractogram, compound 2 remains crystalline and no new phases are observed, which proves that the process happening is heterogenous and our catalyst could be reused several times without losing its crystalline state. 


\section{Materials and Methods}

\subsection{Materials}

All reagents were of reagent grade and used as received without further purification. 3(5)-Methyl-1,2,4-triazole [43] and 3,5-dimethyl-1,2,4-triazole [44,45] were synthesized according to the literature.

\subsection{Methods}

Thermogravimetric analysis (TGA) coupled to differential scanning calorimetry (DSC) was carried out with a NETZSCH 449F3 instrument (Erich NETZSCH GmbH \& Co. Holding KG, Selb, Germany)) at a heating rate of $10 \mathrm{~K} / \mathrm{min}$ in a stream of argon, scanning range-30-800 ${ }^{\circ} \mathrm{C}$. Samples were air-dried for several days prior to analysis. GC-MS analyses were performed on an Agilent 7890A GC combined with an Agilent 5975C mass detector (Agilent Technologies, Santa Clara, CA, USA); carrier gas was helium. IR spectra were recorded on Agilent Cary 630 FTIR spectrometer equipped with a diamond ATR (attenuated total reflectance) tool. NMR spectra were recorded on a Bruker AVANCE III HD instrument (Bruker, Billerica, MA, USA) and are referenced to the solvent residual signal. Elemental analyses were carried out on Carlo Erba CHNS analyser (Val de Reuil, France).

\subsubsection{X-ray Structure Determination}

Single-crystal X-ray diffraction data were collected at $150 \mathrm{~K}$ on a Bruker-DUO APEX CCD diffractometer (graphite monochromatized Mo $\mathrm{K} \alpha$ radiation, $\lambda=0.71073 \AA$, $\varphi$ and $\omega$ scans of narrow frames, Bruker Corporation, Billerica, MA, USA) equipped with a 4 K CCD area detector (Table 3). Absorption corrections were applied using the SADABS program [46]. The crystal structures were solved by direct methods and refined by full-matrix least-squares techniques with the use of the SHELXTL package [47] and Olex2 GUI [48]. Atomic thermal displacement parameters for non-hydrogen atoms were refined anisotropically. The positions of $\mathrm{H}$ atoms were calculated corresponding to their geometrical conditions and refined using the riding model. In the complex 1, both coordinated and solvate water molecules show non-integer occupancies (of ca. 70/30\% correspondingly) as clearly indicated by residual electron density map (Figure S14). Thus, the occupancies were refined with their sum constrained to unity to have reasonable atomic displacement parameters of $\mathrm{O}$ atoms.

\subsubsection{Ligand Synthesis}

General method for preparation of all presented compounds is described below. Completion of the reactions was determined by TLC with bromocresol green solution as a stain.

$10 \mathrm{mmol}$ of the appropriate azole (1H-1,2,4-triazole, 3-methyl-1H-1,2,4-triazole, 3,5-dimethyl-1H-1,2,4-triazole, $1 H$-tetrazole or 5-methyl- $1 H$-tetrazole) and $10 \mathrm{mmol}$ of 1-adamantane carboxylic acid were placed in $20 \mathrm{~mL}$ screwcap vial and dissolved in $10 \mathrm{~mL}$ of $98 \%$ concentrated sulfuric acid. The mixture was cooled to $0{ }^{\circ} \mathrm{C}$ using an ice bath. After cooling, $10 \mathrm{mmol}$ (1010 $\mathrm{mg}$ ) of potassium nitrate were added in small portions over the period of $30 \mathrm{~min}$. Once all of the nitrate has been added, the ice bath was removed, and the mixture was stirred for another $4 \mathrm{~h}$ at room temperature. After $4 \mathrm{~h}$ of stirring, reaction mixture was poured on $100 \mathrm{~g}$ of crushed ice with shaking and allowed to stand until it reached room temperature. Quenched mixture was filtered and neutralized with saturated $\mathrm{NaHCO}_{3}$ solution. Precipitate was filtered, washed with copious amounts of distilled water and dried in vacuum desiccator. Products are sufficiently pure for the synthesis of coordination compounds, but for the analysis the small portions of each compound were recrystallized from the mixture of water/MeOH (9:1).

3-(1,2,4-Triazol-1-yl)-adamantane-1-carboxylic acid (trzadcH) Yield 88\%, colorless crystals. $\mathrm{C}_{13} \mathrm{H}_{17} \mathrm{~N}_{3} \mathrm{O}_{2}$ (247.30): calcd. C 63.14, H 6.93, N 16.99; found C 63.38, H 7.09, N 17.13. Mp = 201-202 ${ }^{\circ} \mathrm{C}$, ${ }^{1} \mathrm{H}$ NMR $\left(400 \mathrm{MHz} \mathrm{CDCl}_{3}\right): \delta=1.67\left(\mathrm{~s}, 2 \mathrm{H}, \mathrm{CH}_{2}\right), 1.82(\mathrm{t}, 2 \mathrm{H}, \mathrm{CH}), 2.08\left(\mathrm{t}, 4 \mathrm{H}, \mathrm{CH}_{2}\right), 2.17(\mathrm{~s}, 2 \mathrm{H}$, $\mathrm{CH}), 2.26\left(\mathrm{~s}, 2 \mathrm{H}, \mathrm{CH}_{2}\right), 7.97(\mathrm{~s}, 1 \mathrm{H}, \operatorname{trz}), 8.59$ (s, $\left.1 \mathrm{H}, \mathrm{trz}\right), 12.53(\mathrm{~s}, 1 \mathrm{H}, \mathrm{COOH}), \mathrm{ppm} .{ }^{13} \mathrm{C}(100 \mathrm{MHz}$, 
$\left.\mathrm{CDCl}_{3}\right): \delta=29.0,34.9,37.7,41.4,42.2,43.6,58.5,141.1,151.3,177.6, \mathrm{ppm}$. FT-IR $\left(\mathrm{cm}^{-1}\right): v=2921(\mathrm{~s})$, 2849 (s), 1682 (s), 1506 (m), 1455 (w), 1363 (w), 1318 (w), 1285 (s), 1229 (s), 1132 (s), 1084 (s), 973 (m), 883 (w), 837 (s), 704 (s). m/z (methyl ester): 261 (100\%), 202 (44\%), 133 (91\%), 100 (58\%).

Crystals suitable for single crystal X-Ray diffraction were obtainted by heating the compound in water to $150{ }^{\circ} \mathrm{C}$ in a sealed ampoule and slow cooling to room temperature.

3-(3-Methyl-1,2,4-triazol-1-yl)-adamantane-1-carboxylic acid (mtrzadcH) Yield 65\%, colorless crystals. $\mathrm{C}_{14} \mathrm{H}_{19} \mathrm{~N}_{3} \mathrm{O}_{2}$ (261.32): calcd. C 64.35, $\mathrm{H}$ 7.33, N 16.08; found C 64.62, H 7.07, N 16.41. Mp = 179-180 ${ }^{\circ} \mathrm{C}$, ${ }^{1} \mathrm{H}$ NMR $\left(400 \mathrm{MHz} \mathrm{CDCl}_{3}\right): \delta=1.66\left(\mathrm{~s}, 2 \mathrm{H}, \mathrm{CH}_{2}\right), 1.80(\mathrm{t}, 2 \mathrm{H}, \mathrm{CH}), 2.04\left(\mathrm{t}, 4 \mathrm{H}, \mathrm{CH}_{2}\right), 2.13(\mathrm{~s}, 2 \mathrm{H}$, $\left.\mathrm{CH}_{2}\right), 2.23(\mathrm{~s}, 5 \mathrm{H}), 8.40(\mathrm{~s}, 1 \mathrm{H}, \mathrm{trz}), 12.34(\mathrm{~s}, 1 \mathrm{H}, \mathrm{COOH}), \mathrm{ppm} .{ }^{13} \mathrm{C}\left(100 \mathrm{MHz}, \mathrm{CDCl}_{3}\right): \delta=14.28,29.0$, 34.9, 37.7, 41.4, 42.2, 43.6, 58.10, 141.5, 159.6, 177.6, ppm. FT-IR $\left(\mathrm{cm}^{-1}\right): v=3131(\mathrm{w}), 2922(\mathrm{~s}), 2960(\mathrm{~s})$, 1685 (s), 1527 (m), 1458 (m), 1320 (m), 1244 (s), 1086 (m), 1023 (m), 867 (s), 717 (s). m/z (methyl ester): 275 (89\%), 216 (28\%), 193 (63\%), $133(100 \%), 91$ (47\%).

3-(3,5-Dimethyl-1,2,4-triazol-1-yl)-adamantane-1-carboxylic acid (dmtrzadcH) Yield 47\%, colourless needles. $\mathrm{C}_{15} \mathrm{H}_{21} \mathrm{~N}_{3} \mathrm{O}_{2}$ (275.35): calcd. C 65.43, $\mathrm{H}$ 7.69, $\mathrm{N} 15.26$; found $\mathrm{C}$ 65.71, H 7.48, $\mathrm{N} 15.49$. $\mathrm{Mp}=244-245^{\circ} \mathrm{C},{ }^{1} \mathrm{H}$ NMR $\left(400 \mathrm{MHz},\left(\mathrm{CD}_{3}\right)_{2} \mathrm{SO}\right): \delta=1.49-1.79(\mathrm{~m}, 7 \mathrm{H}), 2.13(\mathrm{~m}, 7 \mathrm{H}), 2.23(\mathrm{~s}, 4 \mathrm{H})$, 2.49 (s, $4 \mathrm{H}), 12.25$ (s, 1H, COOH), ppm. ${ }^{13} \mathrm{C}\left(100 \mathrm{MHz},\left(\mathrm{CD}_{3}\right)_{2} \mathrm{SO}\right): \delta=14.0,15.9,29.3,34.8,37.6,40.8$, 42.3, 43.0, 60.1, 151.1, 156.6, 177.8, ppm. FT-IR $\left(\mathrm{cm}^{-1}\right): v=3437(\mathrm{w}), 2915(\mathrm{~s}), 2860(\mathrm{~s}), 1691(\mathrm{~s}), 1533(\mathrm{~m})$, 1408 (s), 1347 (m), 1257 (s), 1224 (s), 1078 (s), 989 (m), 891 (m), 851 (m), 739 (m), 693 (s). m/z (methyl ester): 289 (61\%), 230 (25\%), 193 (93\%), 161 (48\%), $133(100 \%), 91(40 \%)$.

3-(Tetrazol-1-yl)-adamantane-1-carboxylic acid (ttzadcH) Yield 81\%, white powder. $\mathrm{C}_{12} \mathrm{H}_{16} \mathrm{~N}_{4} \mathrm{O}_{2}$ (248.28): calcd. C 58.05, H 6.50, N 22.57; found C 58.36, H 6.61, N 22.68. Mp $=195-197{ }^{\circ} \mathrm{C},{ }^{1} \mathrm{H} \mathrm{NMR}$ $\left(400 \mathrm{MHz},\left(\mathrm{CD}_{3}\right)_{2} \mathrm{SO}\right): \delta=1.71(\mathrm{~s}, 2 \mathrm{H}), 1.85(\mathrm{~s}, 4 \mathrm{H}), 2.22(\mathrm{~s}, 4 \mathrm{H}), 2.32(\mathrm{~m}, 4 \mathrm{H}), 8.94(\mathrm{~s}, 1 \mathrm{H}, \mathrm{ttz}), 12.34(\mathrm{~s}$, $1 \mathrm{H}, \mathrm{COOH})$, ppm. ${ }^{13} \mathrm{C}\left(100 \mathrm{MHz},\left(\mathrm{CD}_{3}\right)_{2} \mathrm{SO}\right): \delta=29.06,34.58,37.49,41.24,42.25,43.07,64.09,153.22$, 177.33, ppm. FT-IR ( $\left.\mathrm{cm}^{-1}\right): v=3145(\mathrm{w}), 2911(\mathrm{~s}), 2862(\mathrm{~s}), 1708(\mathrm{~s}), 1458(\mathrm{~m}), 1291(\mathrm{~m}), 1260(\mathrm{w}), 1221$ (s), 1165 (m), 1093 (m), 1092 (m), 1040 (s), 901 (m), 697 (s).

1-(5-Methyl-tetrazol-1-yl)-adamantane 3-carboxylic acid (mttzadcH) Yield 76\%, white powder. C13H18N4O2 (262.31): calcd. C 59.53, H 6.92, N 21.36; found C 59.79, H 6.68, N 21.66. Mp = 179-180 ${ }^{\circ} \mathrm{C}, 1 \mathrm{H} \mathrm{NMR}\left(400 \mathrm{MHz},(\mathrm{CD}[3])_{2} \mathrm{SO}\right): \delta=1.88(\mathrm{~s}, 2 \mathrm{H}), 2.08(\mathrm{~m}, 4 \mathrm{H}), 2.41(\mathrm{~s}, 4 \mathrm{H}), 2.51(\mathrm{~s}, 3 \mathrm{H}), 2.57$ (s, 2 $\mathrm{H}), 2.60$ (s, $2 \mathrm{H}), 11.14$ (s, $1 \mathrm{H}, \mathrm{COOH}), \mathrm{ppm}$. 13C (100 MHz, (CD3)2SO): $\delta=10.82,28.99,34.71,37.30$, 41.19, 42.59, 42.77, 63.46, 162.25, 181.68, ppm. FT-IR $\left(\mathrm{cm}^{-1}\right): v=2932(\mathrm{~s}), 2863(\mathrm{~s}), 1708(\mathrm{~s}), 1501(\mathrm{~m})$, 1458 (m), 1363 (w), 1336 (m), 1208 (s), 1142 (s), 1101 (m), 980 (w), 902 (m), 849 (m), 716 (s), 667 (s).

\subsubsection{Preparation of Coordination Compounds}

All the complexes were prepared under solvothermal conditions as follows. $2 \mathrm{~mL}$ of $0.1 \mathrm{M}$ ligand solution (0.2 mmol) in methanol (compounds 2-4) or DMF (compound 1) was mixed with $1 \mathrm{~mL} 0.1 \mathrm{M}$ solution $(0.1 \mathrm{mmol})$ of appropriate metal nitrate hydrate in a $4 \mathrm{~mL}$ screwcap vial. Vial was placed in oven at $80^{\circ} \mathrm{C}$ for methanol and $120^{\circ} \mathrm{C}$ for DMF for $24 \mathrm{~h}$. Upon cooling to room temperature, crystals suitable for single crystal X-Ray analysis were formed, washed with $4 \mathrm{~mL}$ of fresh solvent and stored under pure solvent.

$\left[\mathrm{Cu}_{2}(\text { trzadc })_{4}\left(\mathrm{H}_{2} \mathrm{O}\right)_{0.7}\right] \cdot D M F \cdot 0.3 \mathrm{H}_{2} \mathrm{O}$ (1) Bright blue crystals. Yield $23 \%$. $\mathrm{C}_{55} \mathrm{H}_{75} \mathrm{Cu}_{2} \mathrm{~N}_{13} \mathrm{O}_{11}$ (1221.35): calcd. C 54.07, H 6.19, N 14.91; found C 54.40, H 6.01, N 15.19. IR, cm ${ }^{-1}$ : 3466 (v, O-H), 2907 (v, C-H), 1663 (va, C-O), 1368 (v, C-O).

$\left[\mathrm{Cu}(\text { trzadc })_{2}(\mathrm{MeOH})\right] \cdot \mathrm{MeOH}$ (2) Pale blue crystals. Yield 40\%. $\mathrm{C}_{28} \mathrm{H}_{40} \mathrm{CuN}_{6} \mathrm{O}_{6}(620.20)$ : calcd. C 54.51, H 6.50, N 13.55; found C 54.24, H 6.37, N 13.80. IR, cm $\mathrm{cm}^{-1}$ : 3338 (v, O-H), 2910 (v, C-H), 1611 (va, $\mathrm{C}-\mathrm{O}), 1346\left(\mathrm{v}_{\mathrm{s}}, \mathrm{C}-\mathrm{O}\right)$.

[Ni(trzadc) $)_{2}(\mathrm{MeOH})_{2}$ ] (3) Pale green plates. Yield 32\%. $\mathrm{C}_{14} \mathrm{H}_{20} \mathrm{~N}_{3} \mathrm{NiO}_{3}$ (337.02): calcd. C 49.87, $\mathrm{H}$ 5.98, N 12.47; found C 49.63, H 6.21, N 12.42. IR, $\mathrm{cm}^{-1}$ : 2895 (v, C-H), 1560 ( $\left.\mathrm{v}_{\mathrm{a}}, \mathrm{C}-\mathrm{O}\right), 1375$ ( $\left.\mathrm{v}_{\mathrm{s}}, \mathrm{C}-\mathrm{O}\right)$.

$\left[\mathrm{Cu}_{2}(\text { mtrzadc })_{3}(\mathrm{MeOH})\right]^{+} \mathrm{NO}_{3}{ }^{-}$(4) Bright green crystals. Yield $36 \% . \mathrm{C}_{43} \mathrm{H}_{58} \mathrm{CuN}_{10} \mathrm{O}_{10}$ (938.53): calcd. C 55.01, H 6.23, N 14.93; found C 54.78, H 6.10, N 14.70. IR, cm ${ }^{-1}: 2913$ (v, C-H), 1606 (va, C-O), 1415 (v, N-O), 1292 (v , C-O). 


\subsubsection{Catalytic Activity Tests}

In a typical procedure, $10 \mathrm{~mL}$ vial was loaded with $0.1 \mathrm{mmol}(6.8 \mathrm{mg})$ of imidazole, $0.15 \mathrm{mmol}$ $(18.3 \mathrm{mg}$ ) of phenylboronic acid $1 \mathrm{~mL}$ of methanol and $6 \mathrm{mg}$ of compound 2 . This mixture was left stirring on an oil bath at $40^{\circ} \mathrm{C}$ for $24 \mathrm{~h}$. Next, the mixture was centrifuged to recover the catalyst and supernatant analyzed by GC to calculate the conversion.

\section{Conclusions}

In summary, we have developed a pathway for the production of a new kind of adamantane-based ligands and successfully employed them for the preparation of several coordination polymers. The proposed method is robust, provides moderate to high yields and is easy to perform. It also allows a facile synthesis of the coordination polymers with mixed coordination environment, which may be very useful as demonstrated by catalytic activity of one of the complexes.

Supplementary Materials: The following are available online at http://www.mdpi.com/1420-3049/24/15/2717/s1, Figure S1: Representation of a layer built from 1D chains of the complexes an solvate molecules for $\mathbf{1}$ and 2, Figure S2: Representation of 1D chains of 1 (a), 2 (b) and 3 (c) showing their similarity, Figure S3: Structure view along 1D chain showing difference between $3(a)$ and 1-2 (b, on the example of 1), Figure S4: Representation of torsion angles of trzadc $^{-}$and mtrzadc $^{-}$ligands on the example of trzadc ${ }^{-}$, Figure S5: Intermolecular hydrogen bonds between molecules of trzadcH, Table S1: Torsion angles (deg.) for trzadc ${ }^{-}$and mtrzadc $^{-}$ligands in the complexes 1-4., Figure S6: The PXRD patterns for compounds 1-4, Figure S7: IR Spectra of trzadc, mtrzadc, dmtradc (a); IR spectra of ttzadc, mttzadc (b); IR spectra of trzadc and compounds 1-3 (c); IR spectra of mtrzadc and compound 4 (d), Figure S8: TGA/DSC curves for compounds 1-4, Figure S9: NMR spectra of the trzadc, Figure S10: NMR spectra of the mtrzadc, Figure S11: NMR spectra of the dmtrzadc, Figure S12: NMR spectra of the ttzadc, Figure S13: NMR spectra of the mtrzadc, Figure S14: Residual electron density map $\left(0.55 \mathrm{e}^{-3}\right.$ level) for the complex 1 with full occupancy of coordinated and solvate water molecules. CCDC 1922178 (1), 1922180 (2), 1922179 (3), 1922177 (4), and 1922176 (trzadcH) contain the supplementary crystallographic data for this paper. These data can be obtained free of charge from the Cambridge Crystallographic Data Centre via www.ccdc.cam.ac.uk/data_request/cif.

Author Contributions: Conceptualization, D.P. and A.P.; Data curation, D.P. and T.S.; Funding acquisition, A.P.; Investigation, D.P. and E.F.; Methodology, D.P. and A.P.; Software, T.S.; Supervision, A.P.; Visualization, T.S.; Writing - original draft, D.P. and T.S.; Writing - review \& editing, A.P.

Funding: The reported study was supported by the Russian Science Foundation, grant No. 19-73-20087.

Conflicts of Interest: The authors declare no conflict of interest.

\section{References}

1. Senchyk, G.A.; Lysenko, A.B.; Boldog, I.; Rusanov, E.B.; Chernega, A.N.; Krautscheid, H.; Domasevitch, K.V. 1,2,4-Triazole functionalized adamantanes: A new library of polydentate tectons for designing structures of coordination polymers. Dalt. Trans. 2012, 41, 8675. [CrossRef] [PubMed]

2. Ermer, O. Fivefold-Diamond Structure of Adamantane-1,3,5,7-tetracarboxylic Acid. J. Am. Chem. Soc. 1988, $110,3747-3754$.

3. Senchyk, G.A.; Lysenko, A.B.; Rusanov, E.B.; Chernega, A.N.; Krautscheid, H.; Domasevitch, K. V Polynuclear and polymeric metal complexes based upon 1,2,4-triazolyl functionalized adamantanes. Inorganica Chim. Acta 2009, 362, 4439-4448. [CrossRef]

4. Chen, B.; Eddaoudi, M.; Reineke, T.M.; Kampf, J.W.; O’Keeffe, M.; Yaghi, O.M. Cu2(ATC)·6H2O: Design of open metal sites in porous metal-organic crystals (ATC: 1,3,5,7-Adamantane Tetracarboxylate). J. Am. Chem. Soc. 2000, 122, 11559-11560.

5. Nasrallah, H.; Hierso, J.-C. Porous Materials Based on 3-Dimensional Td-Directing Functionalized Adamantane Scaffolds and Applied as Recyclable Catalysts. Chem. Mater. 2019, 31, 619-642. [CrossRef]

6. Khanfar, M.A.; Jaber, A.M.; AlDamen, M.A.; Al-Qawasmeh, R.A.; Khanfar, M.A.; Jaber, A.M.; AlDamen, M.A.; Al-Qawasmeh, R.A. Synthesis, Characterization, Crystal Structure, and DFT Study of a New Square Planar $\mathrm{Cu}(\mathrm{II})$ Complex Containing Bulky Adamantane Ligand. Molecules 2018, 23, 701. [CrossRef]

7. Senchyk, G.A.; Lysenko, A.B.; Rusanov, E.B.; Chernega, A.N.; Jezierska, J.; Domasevitch, K.V.; Ozarowski, A. Structure and magnetic behavior of CuII MOFs supported by 1,2,4-triazolyl-bifunctionalized adamantane scaffold. Eur. J. Inorg. Chem. 2012, 5802-5813. 
8. Shimizu, G.K.H.; Vaidhyanathan, R.; Taylor, J.M. Phosphonate and sulfonate metal organic frameworks. Chem. Soc. Rev. 2009, 38, 1430-1449. [CrossRef]

9. Mocanu, T.; Pop, L.; Hadade, N.D.; Shova, S.; Grosu, I.; Andruh, M. Coordination polymers constructed from tetrahedral-shaped adamantane tectons. CrystEngComm 2017, 19, $27-31$.

10. Yang, J.; Ma, J.-F.; Liu, Y.-Y.; Li, S.-L.; Zheng, G.-L. Four Novel 3D Copper(II) Coordination Polymers with Different Topologies. Eur. J. Inorg. Chem. 2005, 2005, 2174-2180.

11. Hoffart, D.J.; Côté, A.P.; Shimizu, G.K.H. An Adamantane-Based Coordination Framework with the First Observation of Discrete Metal Sulfonate Clusters. Inorg. Chem. 2003, 42, 8603-8605. [CrossRef] [PubMed]

12. Ren, C.; Zhang, Y.-N.; Shi, W.-J.; Liu, B.; Wang, Y.-Y.; Shi, Q.-Z. Structural diversity of coordination polymers assembled from adamantane dicarboxylates and conformational bis-triazole ligand. CrystEngComm 2011, 13, 5179. [CrossRef]

13. Travis, J.Z.; Martinez, B.L.; LaDuca, R.L. Structurally Diverse Divalent Metal Adamantanedicarboxylate Coordination Polymers with Hydrogen-bonding Capable Dipyridyl Pillaring Ligands. Zeitschrift für Anorg. und Allg. Chemie 2018, 644, 33-42. [CrossRef]

14. Travis, J.Z.; Pumford, S.R.; Martinez, B.L.; LaDuca, R.L. Nickel adamantanedicarboxylate and adamantanediacetate 2D and 3D coordination polymers with hydrogen-bonding capable dipyridyl ligands. Polyhedron 2018, 142, 25-37. [CrossRef]

15. Qiu, L.; Yu, C.; Wang, X.; Xie, Y.; Kirillov, A.M.; Huang, W.; Li, J.; Gao, P.; Wu, T.; Gu, X.; et al. Tuning the Solid-State White Light Emission of Postsynthetic Lanthanide-Encapsulated Double-Layer MOFs for Three-Color Luminescent Thermometry Applications. Inorg. Chem. 2019, 58, 4524-4533. [CrossRef]

16. Senchyk, G.A.; Lysenko, A.B.; Krautscheid, H.; Rusanov, E.B.; Chernega, A.N.; Krämer, K.W.; Liu, S.X.; Decurtins, S.; Domasevitch, K.V. Functionalized adamantane tectons used in the design of mixed-ligand copper(II) 1,2,4-triazolyl/carboxylate metal-organic frameworks. Inorg. Chem. 2013, 52, 863-872. [CrossRef] [PubMed]

17. Kuehl, C.J.; Kryschenko, Y.K.; Radhakrishnan, U.; Seidel, S.R.; Huang, S.D.; Stang, P.J. Self-assembly of nanoscopic coordination cages of D(3h) symmetry. Proc. Natl. Acad. Sci. USA 2002, 99, 4932-4936. [CrossRef]

18. Marchenko, R.; Potapov, A. 1,3-Bis(1,2,4-triazol-1-yl)adamantane. Molbank 2017, 2017, M968. [CrossRef]

19. Fujimoto, H.; Kitagawa, Y.; Hao, H.; Fukui, K. Chemical Reactivity of Adamantane and Related Compounds. Bull. Chem. Soc. Jpn. 2006, 43, 52-56. [CrossRef]

20. Fort, R.C.; Von Schleyer, P.R. Adamantane: Consequences of the diamondoid structure. Chem. Rev. 1964, 64, 277-300. [CrossRef]

21. SMITH, G.W.; WILLIAMS, H.D. Some Reactions of Adamantane and Adamantane Derivatives. J. Org. Chem. 1961, 26, 2207-2212. [CrossRef]

22. Tsypin, V.G.; Kachala, V.V.; Ugrak, B.I.; Golod, E.L. Adamantylation of indazole and its C-nitro derivatives. Russ. J. Org. Chem. 2002, 38, 90-94. [CrossRef]

23. Amandurdyev, A.D.; Saraev, V.V.; Polyakova, I.N.; Golod, E.L. Adamantylazoles: IX. Acid-catalyzed Adamantylation of 1,2,4-Triazol-3-thione. Russ. J. Gen. Chem. 2005, 75, 130-133. [CrossRef]

24. Saraev, V.V.; Kanakina, T.P.; Pevzner, M.S.; Golod, E.L.; Ugrak, B.I.; Kachala, V.V. Adamantylazoles. Acid-catalyzed adamantylation of 1,2,4-triazoles. Chem. Heterocycl. Compd. 1996, 32, 928-936. [CrossRef]

25. Raenko, G.F.; Korotkikh, N.I.; Pekhtereva, T.M.; Shvaika, O.P. Adamantylation of Imidazoles and Benzimidazole. Russ. J. Org. Chem. 2001, 37, 1153-1157. [CrossRef]

26. Gavrilov, A.S.; Golod, E.L.; Kachala, V.V.; Ugrak, B.I. Adamantylazoles: IV. Acid-Catalyzed Adamantylation of Pyrazoles. Russ. J. Org. Chem. 2001, 37, 1741-1746. [CrossRef]

27. Terekhova, M.I.; Petrov, E.S.; Rokhlina, E.M.; Kravtsov, D.N.; Shatenshtein, A.I. Equilibrium NH acidity of nitrogen heterocycles. Chem. Heterocycl. Compd. 1979, 15, 904-908. [CrossRef]

28. Nakamoto, K.; Fujita, J.; Tanaka, S.; Kobayashi, M. Infrared Spectra of Metallic Complexes. IV. Comparison of the Infrared Spectra of Unidentate and Bidentate Metallic Complexes. J. Am. Chem. Soc. 1957, 79, 4904-4908. [CrossRef]

29. Nakamoto, K. Infrared and Raman Spectra of Inorganic and Coordination Compounds. In Handbook of Vibrational Spectroscopy; Griffiths, P.R., Ed.; John Wiley \& Sons, Ltd: Chichester, UK, 2006.

30. Aijaz, A.; Lama, P.; Sañudo, E.C.; Mishra, R.; Bharadwaj, P.K. Coordination polymers of various architectures built with mixed imidazole/benzimidazole and carboxylate donor ligands and different metal ions: Syntheses, structural features and magnetic properties. New J. Chem. 2010, 34, 2502. [CrossRef] 
31. Ben Kiran, A.; Mocanu, T.; Pöllnitz, A.; Shova, S.; Andruh, M.; Silvestru, C. Triphenylbismuth(v) di[(iso)nicotinates]-transmetallation agents or divergent organometalloligands? First organobismuth(v)-based silver(i) coordination polymers. Dalt. Trans. 2018, 47, 2531-2542. [CrossRef]

32. Wang, D.-W.; Wang, T.; Du, L.; Zhou, J.; Yan, T.; Zhao, Q.-H. Four supramolecular transition metal(II) complexes based on triazole-benzoic acid derivatives: Crystal structure, Hirshfeld surface analysis, and spectroscopic and thermal properties. Struct. Chem. 2018, 29, 1013-1023. [CrossRef]

33. Chandrasekhar, V.; Thirumoorthi, R. Reactions of 3,5-Pyrazoledicarboxylic Acid with Organotin Chlorides and Oxides. Coordination Polymers Containing Organotin Macrocycles. Organometallics 2009, 28, 2096-2106. [CrossRef]

34. Feng, C.; Ma, Y.-H.; Zhang, D.; Li, X.-J.; Zhao, H. Highly efficient electrochemiluminescence based on pyrazolecarboxylic metal organic framework. Dalt. Trans. 2016, 45, 5081-5091. [CrossRef] [PubMed]

35. Liu, Y.; Meng, B.; Wang, X.; Yang, R.; Li, W. Synthesis, Crystal Structure and Magnetic Property of a New Three-Dimensional Mn-Na Heteronuclear Coordination Complex Based on 3,5-Pyrazoledicarboxylic Acid. J. Clust. Sci. 2016, 27, 1253-1261. [CrossRef]

36. Kivi, C.E.; Gelfand, B.S.; Dureckova, H.; Ho, H.T.K.; Ma, C.; Shimizu, G.K.H.; Woo, T.K.; Song, D. 3D porous metal-organic framework for selective adsorption of methane over dinitrogen under ambient pressure. Chem. Commun. 2018, 54, 14104-14107. [CrossRef]

37. Tu, B.; Pang, Q.; Xu, H.; Li, X.; Wang, Y.; Ma, Z.; Weng, L.; Li, Q. Reversible Redox Activity in Multicomponent Metal-Organic Frameworks Constructed from Trinuclear Copper Pyrazolate Building Blocks. J. Am. Chem. Soc. 2017, 139, 7998-8007. [CrossRef] [PubMed]

38. Zhou, X.-H.; Chen, Q. A three-dimensional coordination polymer based on 1,2,3-triazole-4,5-dicarboxylic acid (H3 tda): \{[Cd12(tda)8(H2O)11] • (H2O)6.25\} n. Crystallogr. Reports 2017, 62, 238-241. [CrossRef]

39. Leong, W.L.; Vittal, J.J. One-demensional coordination polymers: Complexity and diversity in structures, properties, and applications. Chem. Rev. 2011, 111, 688-764. [CrossRef] [PubMed]

40. Loukopoulos, E.; Kostakis, G.E. Review: Recent advances of one-dimensional coordination polymers as catalysts. J. Coord. Chem. 2018, 71, 371-410. [CrossRef]

41. Zu, W.; Liu, S.; Jia, X.; Xu, L. Chemoselective $N$-arylation of aminobenzene sulfonamides via copper catalysed Chan-Evans-Lam reactions. Org. Chem. Front. 2019, 6, 1356-1360. [CrossRef]

42. Dar'in, D.; Krasavin, M. The Chan-Evans-Lam N-Arylation of 2-Imidazolines. J. Org. Chem. 2016, 81, 12514-12519. [CrossRef] [PubMed]

43. Faridoon; Hussein, W.M.; Vella, P.; Islam, N.U.; Ollis, D.L.; Schenk, G.; McGeary, R.P. 3-Mercapto-1,2,4-triazoles and $\mathrm{N}$-acylated thiosemicarbazides as metallo- $\beta$-lactamase inhibitors. Bioorg. Med. Chem. Lett. 2012, 22, 380-386. [CrossRef] [PubMed]

44. Cheng, L.; Zhang, W.X.; Ye, B.H.; Lin, J.B.; Chen, X.M. In situ solvothermal generation of 1,2,4-triazolates and related compounds from organonitrile and hydrazine hydrate: A mechanism study. Inorg. Chem. 2007, 46, 1135-1143. [CrossRef] [PubMed]

45. Vereshchagina, T.N.; Lopyrev, V.A.; Pevzner, M.S.; Kogan, L.M. Synthesis of derivatives of 1, 2, 4-triazole-3, 5-dicarboxylic acid. Chem. Heterocycl. Compd. 1972, 5, 681-682. [CrossRef]

46. APEX2 (Version 2.0); SAINT (Version 8.18c); SADABS (Version 2.11). Bruker Advanced X-ray Solutions; Bruker AXS Inc.: Madison, WI, USA, 2000-2012.

47. Sheldrick, G.M. IUCr Crystal structure refinement with SHELXL. Acta Crystallogr. Sect. C Struct. Chem. 2015, 71, 3-8. [CrossRef] [PubMed]

48. Dolomanov, O.V.; Bourhis, L.J.; Gildea, R.J.; Howard, J.A.K.; Puschmann, H. OLEX2: A complete structure solution, refinement and analysis program. J. Appl. Crystallogr. 2009, 42, 339-341. [CrossRef]

Sample Availability: Samples of the compounds reported are available from the authors. 